\title{
Thermodynamics of Supramolecule Formation between Metal Porphyrin and Pyridine Substituted $N$-Methylpyrrolidinyl-[60] fullerene
}

\author{
Tatyana N. Lomova, ${ }^{a}$ Michael E. Malov, ${ }^{\mathrm{b}}$ Michael V. Klyuev, ${ }^{\mathrm{b}}$ and Pavel A. Troshin ${ }^{\mathrm{c}}$ \\ anstitute of the Solution Chemistry of Russian Academy of Sciences, Ivanovo, 153045, Russia \\ 'Ivanovo State University, Ivanovo, 153025, Russia \\ 'Institute of Problems of Chemical Physics of Russian Academy of Sciences, Chernogolovka, 142432, Russia \\ ${ }^{\circledR}$ Corresponding author E-mail: tnl@isc-ras.ru
}

\begin{abstract}
Thermodynamic characteristics, mechanism, and spectral manifestations of consecutive reactions between (5,10,15,20-tetraphenylporphyrinato)(chloro)indium(III) ((Cl)InTPP) and organic base 2'-(4-pyridyl)-1'-methylpyrrolidinyl-[60]fullerene $(P y F)$ in chloroform were studied using spectrophotometric titration and physicochemical analysis of intermediate forms. The consecutive coordination of two PyF molecules $\left(K_{1}=6.9 \cdot 10^{4}, K_{2}=9.3 \cdot 10^{3} \mathrm{l} / \mathrm{mol}\right.$ at $298 \mathrm{~K})$ with the formation of $(\mathrm{Cl})(\mathrm{PyF}) \operatorname{InTPP}$ and $(\mathrm{Cl})(\mathrm{PyF})_{2}$ InTPP, and addition of three other PyF molecules on complex periphery producing $(\mathrm{Cl})(\mathrm{PyF})_{2} \operatorname{InTPP} \cdot 3(\mathrm{PyF})\left(K_{3}=2.3 \mathrm{l}^{3} / \mathrm{mol}^{3}\right)$ were observed at the first, second, and third steps. The third reaction stage most likely corresponds to $\pi-\pi$ complex formation equilibrium between the aromatic complex and PyF with a 1:3 stoichiometry. Perspectives for use of PyF-metalloporphyrin complex as a photovoltaic material are considered.
\end{abstract}

Keywords: Metal porphyrin, pyridine substituted pyrrolidinyl-[60]fullerene, supramolecule complex formation.

\section{Introduction}

Currently, studies of supramolecular interactions between metalloporphyrins and substituted fullerenes as new complexation ligands have very high importance for understanding the principles of action of reaction center in natural and technical photosynthetic antenna models. The additional coordination of nucleophilic particles (molecules and anions) to metalloporphyrins is the simplest example of supramolecule formation, which can be studied in a most convenient way in a liquid inert solvent. The majority of such studies during recent years, ${ }^{[1-5]}$ however, were directed on organized or chaotically built layers of complexes of cyclic tetrapyrrole ligands. Studies of solid fullereneporphyrin/phthalocyanine systems allow to characterize the photoinduced electron transfer and optical spectra. They, however, give no new knowledge about the nature of interactions and the stability of these supramolecules. The

Ломова Татьяна Николаевна, родилась в 1950 2. В 1968 - 1973 г2. обучалась в Ивановском химико-технологическом институте (ИХТИ), занимаясь по индивидуальному плану под руководством Б. Д. Березина. В 1973 - 1976 г2. обучалась в очной аспирантуре ИХТИпод руководством Б. Д. Березина и А. С. Акопова и в 1976 г. защитила кандидатскую диссертацию на тему «Синтез и исследование комплексных соединений полимерных фталочиининов с мостиковыми группами». С 1977 по 1979 гг. и с 1980 по 1991 га. работала соответственно на кафедре органической химии ИХТИ и в Отделе химии порфиринов ИХР РАН,

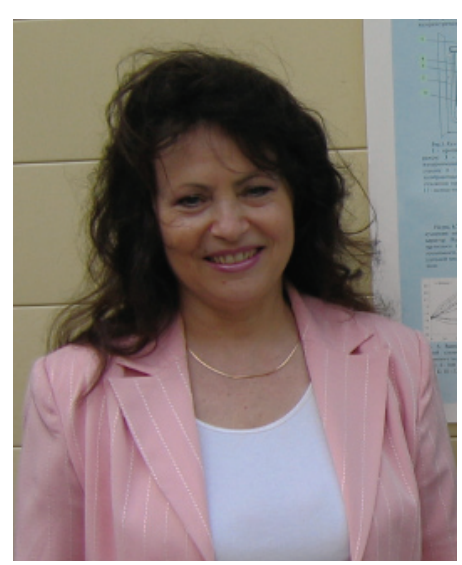
RAS (Ivanovo) which were headed by Prof. B. D. Berezin. In 1990 she received the degree "Doctor of Chemical Sciences" for the dissertation "Reactions of solvo-protolityc dissociation and factors stabilizing metalloporphyrins in solutions". Since 1992 she is Head of the Department Synthesis and reactivity of metalloporphyrins in solutions at Institute of Solution Chemistry $R A S$ and her current research interests are focused on stady of mixed complex compounds with porphyrin ligands. 
determination of these characteristics in solutions indicates paths for the optimization of fullerene-porphyrin architectures and opens the possibility of the intentional search of substances for practical applications. As a continuation of studies $^{[6]}$ of additional coordination reactions on porphyrin complexes of multiple-charge metal cations as compounds with enhanced coordination unsaturation of the central atom, we studied the thermodynamic characteristics of the reaction of $(5,10,15,20$-tetraphenylporphyrinato)(chloro)indium(III) ((Cl)InTPP) with organic N-base 2'-(4-pyridyl)-1'-metylpyrrolidinyl-[60]fullerene (PyF) in chloroform.

\section{Experimental}

(Cl)InTPP was prepared according as described earlier ${ }^{[7]}$ by the coordination reaction of $\mathrm{H}_{2}$ TPP with $\mathrm{InCl}_{3} \cdot 3 \mathrm{H}_{2} \mathrm{O}$ in a $1: 2.5$ molar ratio in boiling phenol. After the synthesis, the compound was isolated and purified by multiple washing of the cooled reaction mixture in chloroform with warm water and was doubly purified by column chromatography on $\mathrm{Al}_{2} \mathrm{O}_{3}$ column using chloroform as an eluant. Yield $60 \%$. Found: In $15.0 \pm 0.35 \% . \mathrm{C}_{44} \mathrm{H}_{28} \mathrm{~N}_{4} \mathrm{ClIn}$ requires In $15.05 \%$. UV-vis $\left(\mathrm{CHCl}_{3}\right) \lambda_{\text {max }} \mathrm{nm}(\lg \varepsilon)$ : 628 (3.30), 599 (3.95), 559 (4.32), 520 (3.59), 420 (4.98). ${ }^{~} \mathrm{H} \mathrm{NMR}\left(\mathrm{CDCl}_{3}\right) \delta_{\mathrm{H}}$ ppm: 9.07 (8H, $\beta$-protons), 8.38 and 8.12 ( $8 \mathrm{H}, o$-protons), $7.80(8 \mathrm{H}$, $m$-protons), 7.75 (4H, $p$-protons).

2'-(4-Pyridyl)-1'-methylpyrrolidinyl-[60]fullerene was prepared according to ${ }^{[8]}$ by the reaction in toluene between $\mathrm{C}_{60}$ and azomethinilide that was synthesized from $N$-methylglycine and 4-carbonylpyridine.

The thermodynamic characteristics of reactions of (Cl)InTPP with PyF in chloroform were studied by spectrophotometric titration. The optical densities of a series of solutions in freshly distilled chloroform with $C_{(\mathrm{Cl}) \mathrm{nTPP}}=0.86$ $10^{-7} \mathrm{~mol} / \mathrm{l}$ and various concentrations of PyF were measured at the working wavelength $560 \mathrm{~nm}$ at $298 \mathrm{~K}$. Solutions were held at a constant temperature in a special chamber mounted in the cell compartment of a spectrophotometer. Temperature was maintained constant within $\pm 0.1 \mathrm{~K}$. The equilibrium constants of reactions were calculated by the equation derived on the basis of the mass action and Buger-Lambert-Beer (for a mixture of two colored compounds) laws (1), where $C^{\circ}{ }_{\mathrm{MP}}, C_{\mathrm{L}}$ are the initial concentrations of metalloporphyrin and PyF, respectively, in chloroform; $A_{\mathrm{o}}, A_{\mathrm{p}}, A_{\infty}$ are the optical densities at the working wavelength for solutions of metalloporphyrin, equilibrium mixture at a certain concentration of $\mathrm{PyF}$, and reaction product, respectively; and $n$ is the number of PyF molecules participating in the reaction.

$$
K=\frac{\frac{A_{\mathrm{P}}-A_{0}}{A_{\infty}-A_{0}}}{1-\frac{A_{\mathrm{P}}-A_{0}}{A_{\infty}-A_{0}}} \cdot \frac{1}{\left(C_{\mathrm{L}}-C_{\mathrm{MP}}^{0} \frac{A_{\mathrm{P}}-A_{0}}{A_{\infty}-A_{0}}\right)^{\mathrm{n}}}
$$

The optimization of $n$ and $K$ values and the determination of the root-mean-square deviations for $K$ were performed by the least squares method using the Microsoft Excel program. The relative error in $K$ values was $20-30 \%$. The electronic absorption spectra (quartz cell $1 \pm 0.001 \mathrm{~cm}$ thick, $298 \mathrm{~K}$ ) and NMR spectra (tetramethylsilane as internal reference) were recorded on SF26 and Agilent 8453 UV-vis and Bruker $(200 \mathrm{MHz})$ instruments, respectively. The elemental analysis data were obtained on AAS1 atomic-absorption spectrometer. Quantum-chemical calculations were performed by the PM3 method with complete geometry optimization. Calculations were continued until a gradient of 0.076 $-0.100 \mathrm{~kJ} /(\mathrm{mol} \cdot \AA)$ was attained.

\section{Results and Discussion}

According to X-ray structure analysis results, ${ }^{[9]} \mathrm{In}-\mathrm{N}$ and $\mathrm{In}-\mathrm{Cl}$ bond lengths and the $\mathrm{In}-\mathrm{C}_{\mathrm{t}}$ distance $\left(\mathrm{C}_{\mathrm{t}}\right.$ is the center of the coordination cavity of porphyrin) are 2.156 , 2.369 , and $0.71 \AA$, respectively. The In atom in $(\mathrm{Cl}) \operatorname{InTPP}$ is displaced from the plane of the coordinating porphyrin cavity toward the $\mathrm{Cl}$-axial ligand. The peculiar structure of the five-coordinate $(\mathrm{Cl})$ InTPP complex is responsible for the special features of reactions with the additional coordination of base molecules.

A study of the electronic absorption spectra of (Cl)InTPP complex in chloroform - PyF mixtures over the whole range of component concentrations and the spectrophotometric titration of (Cl)InTPP solution in chloroform by PyF at the working wavelength are indicative of three-step transformation in (Cl)InTPP - PyF system (Figure 1). All the three reaction stages are reversible. This was substantiated

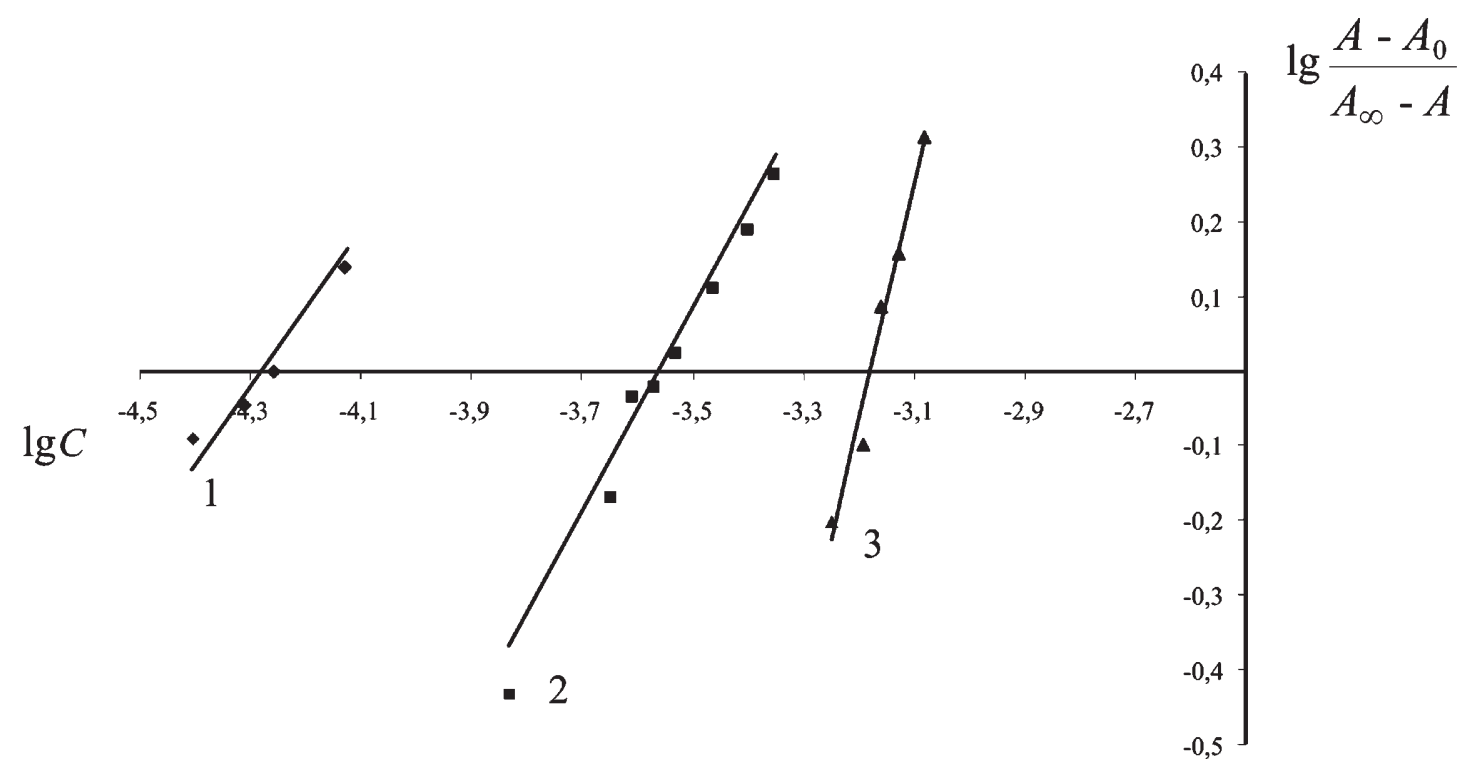

Figure 1. Dependences $\lg \left[\left(A_{\mathrm{p}}-A_{0}\right) /\left(A_{\infty}-A_{\mathrm{p}}\right)\right]-\lg C_{\mathrm{L}}$ for the reaction of $(\mathrm{Cl}) \operatorname{InTPP}$ with PyF in chloroform at the (1) first, (2) second, and (3) third stages $\left(\mathrm{R}^{2}=0.967,0.974\right.$, and 0.974 , respectively). 


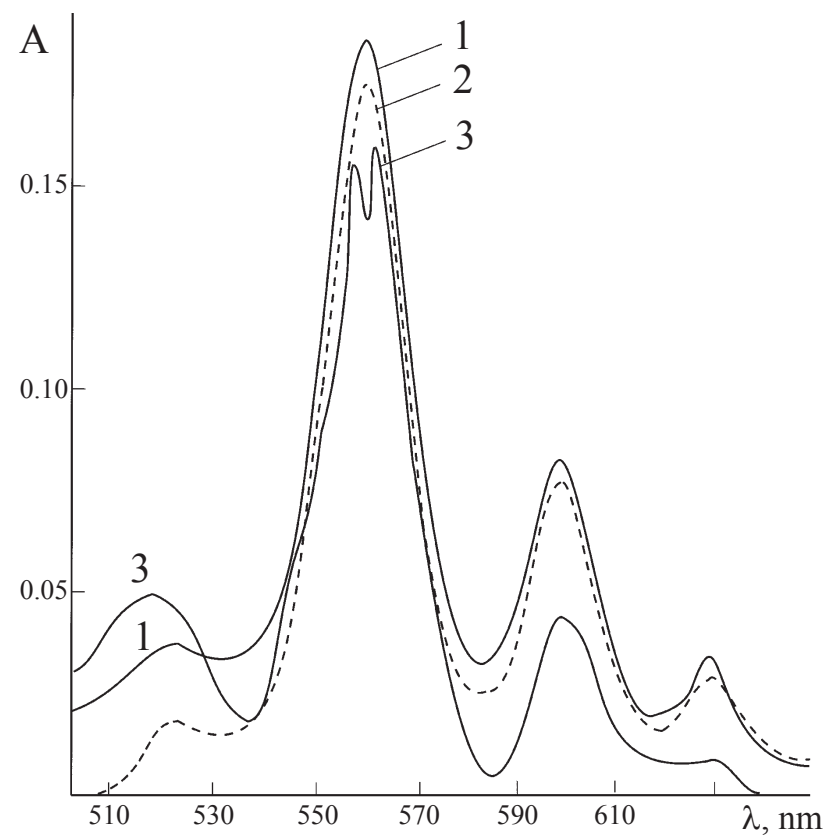

Figure 2. UV-vis spectra of $(\mathrm{Cl}) \operatorname{InTPP}$ in chloroform $\left(C_{(\mathrm{Cl}) \operatorname{InTP}}=\right.$ $0.86 \cdot 10^{-7} \mathrm{~mol} / \mathrm{l}$ ) at various concentration of PyF: (1) $3.96 \cdot 10^{-5},(2)$ $2.47 \cdot 10^{-4}$ and (3) $7.45 \cdot 10^{-4} \mathrm{~mol} / \mathrm{l}$. The spectra correspond to the reaction products at the (1) first, (2) second, and (3) third stages. Absorbing layer thickness $1.000 \mathrm{~cm}$.

by study of electronic absorption spectrum trends during the dilution of solutions with respect to $\mathrm{PyF}$ (Figure 2 ). The composition of the coordination sphere of step reaction products was substantiated by spectrophotometric experiments and PM3 calculations (Table 1).

During the titration process the band intensity $\left(\lambda_{\max } 560\right.$ $\mathrm{nm})$ in the UV-vis spectra is decreased without noticeable shifts of the band maxima and series of isosbestic points corresponding to the first and at second stages are observed $\left(C_{\mathrm{PyF}}\right.$ range is $(1.48 \div 8.88) \cdot 10^{-5}$ and $(1.23 \div 4.93) \cdot 10^{-4}$ $\mathrm{mol} / \mathrm{l}$, respectively). The $K_{1}$ constant for the first stage is $6.92 \cdot 10^{4} \mathrm{l} / \mathrm{mol}$ at $298 \mathrm{~K}$. It is substantially higher than is usually determined for the coordination of bases by metalloporphyrins with a mixed coordination sphere. ${ }^{[10]}$
It was found experimentally that equilibrium at the first stage was attained immediately after the mixing of the reagents. The stoichiometry of the reaction between $(\mathrm{Cl})$ InTPP and PyF at the first stage (1:1) was determined by $\lg \left[\left(A_{\mathrm{p}}-A_{0}\right) /\left(A_{\infty}-A_{\mathrm{p}}\right)\right]-\lg C_{\mathrm{L}}$ dependence (Figure 1, straight line $1(\operatorname{tg} \alpha=0.86))$. Equilibrium mixtures are stable in time. The stoichiometric ratio between the reagents was 1:1, and the absence in the spectra of noticeable absorption band shifts and a comparatively high equilibrium constant value allowed us to suggest that, at the first stage of the reaction of (Cl)InTPP with PyF the coordination of PyF occurs to the sixth coordination place. According to quantum chemical calculations (Table 1) the base is probably coordinated into the trans-position with respect to $\mathrm{Cl}$ (Figure 3), i.e. coordination on the side to which the In atom is displaced from the coordination center is sterically hindered.

Equilibrium at the second stage is also established immediately after the mixing of solutions. As at the first stage, it remains stable in time. The equilibrium constant $K_{2}$ is $9.62 \cdot 10^{3} \mathrm{l} / \mathrm{mol}$, which is seven times smaller than $K_{1}$. This is indicative of worse conditions for the coordination of the second PyF molecule by the six-coordinated $(\mathrm{Cl})(\mathrm{PyF})$ InTPP complex. There is no any displacement of $\mathrm{Cl}^{-}$acido ligand from the coordination sphere (Table 1, Figure 3). The stoichiometry of the reaction of $(\mathrm{Cl}) \operatorname{InTPP}$ with PyF is $1: 1$ (Figure 1, straight line 2, $\operatorname{tg} \alpha=1.3$ ). This is in agreement with our suggestion. The formation of the seven-coordinated complex likely results in a shift of the central In atom toward the $\mathrm{N}_{4}$ porphyrin plane (the value of $l\left(\mathrm{~N}_{\text {porph }}\right.$-In) changes from 2.078 to 2.099), but the structure of $\mathrm{InN}_{4}$ fragment remains pyramidal with a more or less regular square in the base, which follows from the absence of a noticeable displacement of the absorption band in the electronic absorption spectrum (Figure 2). It is known, the formation of indium(III) complexes with the coordination number 7 is less probable than the formation of six-coordinated complexes. ${ }^{[1]}$ According to the data on ten thousands of compounds with structures determined by X-ray diffraction, the distribution of $\mathrm{In}^{\mathrm{III}}$ complexes with the coordination numbers $5,6,7$, and 8 is as follows: $19,16,5$, and 2 .

Table 1. Some geometrical and energetic parameters for the optimized (PM3) structures.

\begin{tabular}{|c|c|c|c|c|c|c|}
\hline Parameter & PyF & (CI)InTPP & $\begin{array}{c}(\mathrm{Cl})(\mathrm{PyF}) \mathrm{InTPP} \\
(\text { trans })\end{array}$ & $\begin{array}{c}(\mathrm{Cl})(\mathrm{PyF}) \operatorname{InTPP} \\
(\text { cis })\end{array}$ & $\begin{array}{c}(\mathrm{Cl})(\mathrm{PyF}) \operatorname{InTPP} \\
\left({\text { trans })^{\mathrm{a}}}^{2}\right.\end{array}$ & $(\mathrm{Cl})(\mathrm{PyF})_{2} \operatorname{InTPP}$ \\
\hline$l_{\mathrm{In}-\mathrm{Cl}}$ & & 2.524 & 2.651 & 4.034 & 2.651 & 2.931 \\
\hline$l_{\mathrm{N}_{\text {porph }}}{ }^{\text {In }}$ & & 2.071 & 2.078 & 2.097 & 2.078 & 2.099 \\
\hline$l_{\mathrm{N}_{\mathrm{cis}}-\mathrm{In}}$ & & & & 2.087 & & 2.106 \\
\hline$l_{\mathrm{N}_{\text {trans }}-\mathrm{In}}$ & & & 2.158 & & & 2.186 \\
\hline $\mathrm{q}_{\mathrm{In}}$ & & -0.223 & -0.279 & -0.237 & -0.279 & -0.415 \\
\hline $\mathrm{q}_{\mathrm{Cl}}$ & & -0.259 & -0.393 & -0.113 & -0.393 & 4.056 \\
\hline $\mathrm{q}_{\mathrm{N}_{\text {cis }}}$ & -0.069 & & & -0.071 & & -1.007 \\
\hline $\mathrm{q}_{\mathrm{N}_{\text {trans }}}$ & & & 0.067 & & 0.067 & 0.118 \\
\hline$E_{\text {bonds }}$ & -11531.3 & -9269.5 & -20731.1 & -20716.5 & -20641.3 & -32227.9 \\
\hline E & -196240.6 & -153580.4 & -349751.3 & -349736.7 & -349661.6 & -545957.5 \\
\hline$Q_{\mathrm{f}}$ & 836.3 & 247.5 & 1153.4 & 1168.0 & 1243.2 & 2024.1 \\
\hline$\Delta E_{\text {bonds }}$ & & & -42.9 & 94.6 & 144.4 & -102.5 \\
\hline
\end{tabular}

\footnotetext{
${ }^{\text {a }} \mathrm{PyF}$ is coordinated as complementary ligand.
} 


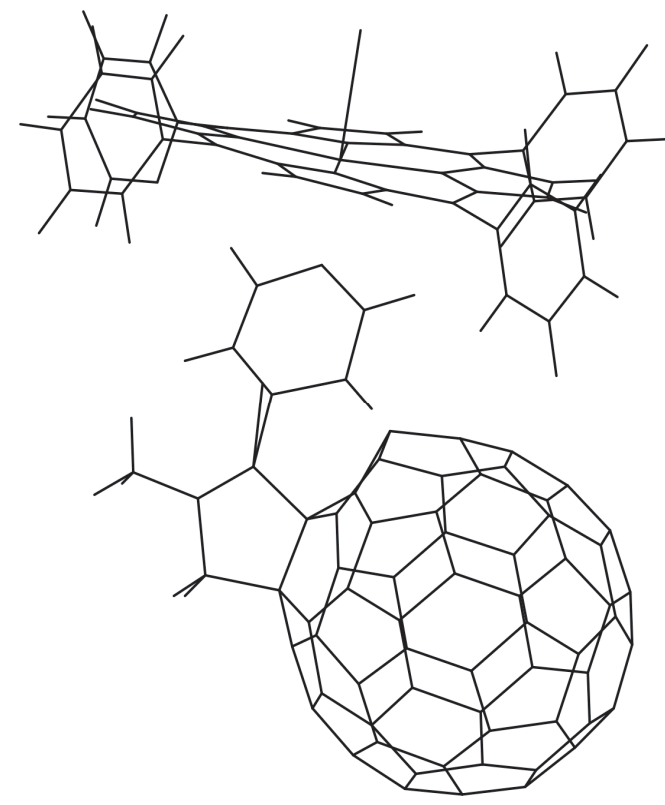

$(\mathrm{Cl})(\mathrm{PyF}) \operatorname{InTPP}($ trans)

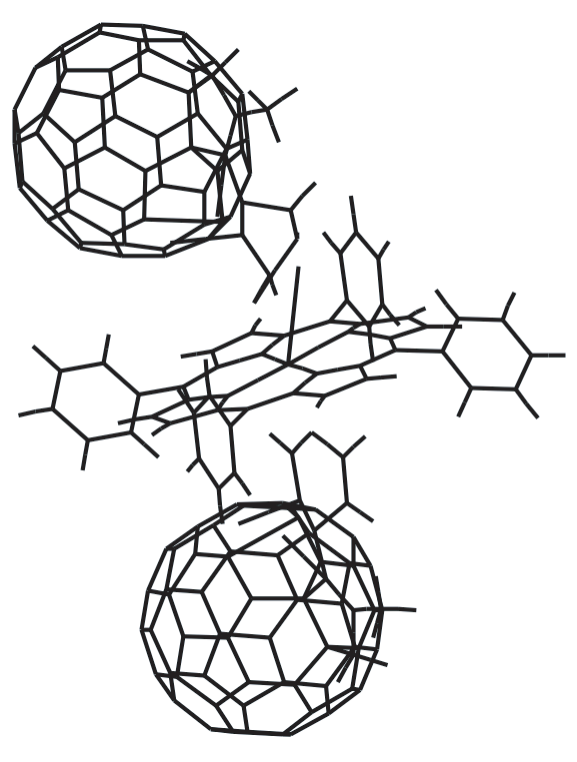

$(\mathrm{Cl})(\mathrm{PyF})_{2} \operatorname{InTPP}$

Figure 3. Optimized structures of six- and seven-coordinated fullerene-porphyrins.

At the third reaction stage three $\mathrm{PyF}$ molecules participate in equilibrium (Figure 1 , line $3, \operatorname{tg} \alpha=3.1$ ). These molecules cannot enter into the coordination sphere of In because of its saturation. Taking into account what is known about the presence of solvents in crystal lattices of metalloporphyrins, ${ }^{[12]}$ specific $\pi-\pi$ interaction between the electron systems of PyF molecules and the coordinated aromatic macroring can be suggested. At this stage, splitting of the band $560 \mathrm{~nm}$ in UV-vis spectrum into two components of 556 and $561 \mathrm{~nm}$ is observed for the first time for the reacting system (Figure 2). The equilibrium constant is $K_{3}=2.34 \cdot 10^{3} \mathrm{l}^{3} / \mathrm{mol}^{3}$. Changes in the electronic absorption spectrum and in the constant of complex formation can mean the transition to solvate of the $(\mathrm{Cl})(\mathrm{PyF})_{2}$ InTPP with three PyF molecules. The results of quantum chemical calculations (Figure 3) show that even when interaction occurs with the first PyF molecule, two aromatic systems are not indifferent to each other, because, in the isolated $(\mathrm{Cl})$ InTPP + PyF system, the arrangement of the pyridine ring of the coordinated PyF molecule is substantially different from axial.

The data of our work show that the mixed complex of porphyrin with multiple-charge cation and pyridine substituted fullerene is the self-organizing system having high stability in the solutions. It is shown ${ }^{[13,14]}$ that the photoinduced separation of charge takes place in these systems. Thus, we deal with the model of the photosynthetic antenna. In this respect the presence of the intensive absorption band at $420 \mathrm{~nm}$ in the electronic spectrum of (Cl)InTPP (see Experimental) seems to be very promisable.

Acknowledgments. This work was financially supported by grants of Presidium of Russian Academy of Sciences, Program no. 18, and Analytic Departmental Special Purpose
Program "The Development of Scientific Potential of the Higher School," project no. 2.2.1.1.2820.

\section{References}

1. Loi M.A., Denk P., Hoppe H., Neugebauer H., Winder C., Meissner D., Brabec C., Sariciftci N. S., Gouloumis A., Vazquez P., Torres T. J. Mater. Chem. Rev. 2003, 13, 700.

2. Drechsel J., Mannig B., Kozlovski F., Gebeyehu D., Werner A., Koch M., Leo K., Pfeiffer M. Thin Solid Films 2004, 451, 515.

3. Peumans P., Forrest S. R. Appl. Phys. Lett. 2001, 79, 126.

4. Ciccarella G., Spadavecchia J., Rella R., Vasapollo G., Mastrerilli P., Suranna G.P. Biosensors and Bioelectronics 2006, 22, 415 .

5. Mahajan R.K., Kaur R., Miyake H., Tsukube H. Anal. Chim. Acta 2007, 584, 89.

6. Lomova T., Malov M., Klyuev M. Russ. J. Phys. Chem. A 2009, 83, 913.

7. Lomova T., Mozhzhukhina E., Shormanova L., Berezin B. Zh. Obshch. Khim. 1989, 59, 2317 (in Russ).

8. Prato M., Maggini M., Giacometti C., Scorrano G., Sandona G., Farnia G. Tetrahedron 1996, 52, 5221.

9. Ball R.G., Lee K.M., Marshall A.G., Trotter J. Inorg. Chem. 1980, 19, 1463.

10. Lomova T.N., Motorina E.V., Ovchenkova E.N., Klyueva M.E. Russ. Chem. Bull. 2007, 56, 660.

11. Solovjev V.P, Stuklova M.S., Kotlunova E.V., Kochanova N.N. Koord. Khim. 2003, 29, 711 (in Russ).

12. Scheidt W.R. In: The Porphyrin Handbook (Kadish K.M., Smith K.M., Guilard R., Eds.) Vol. 3, Academic Press, 2000, 49.

13. Koeppe R., Troshin P., Luybovskaya R., Sariciftci N. Appl. Phys. Lett. 2005, 87, 244102.

14. Koeppe R., Troshin P., Fuchsbauer A., Luybovskaya R., Sariciftci N. Fuller. Nanotub. Carb. Nanosruct. 2006, 14, 441. 